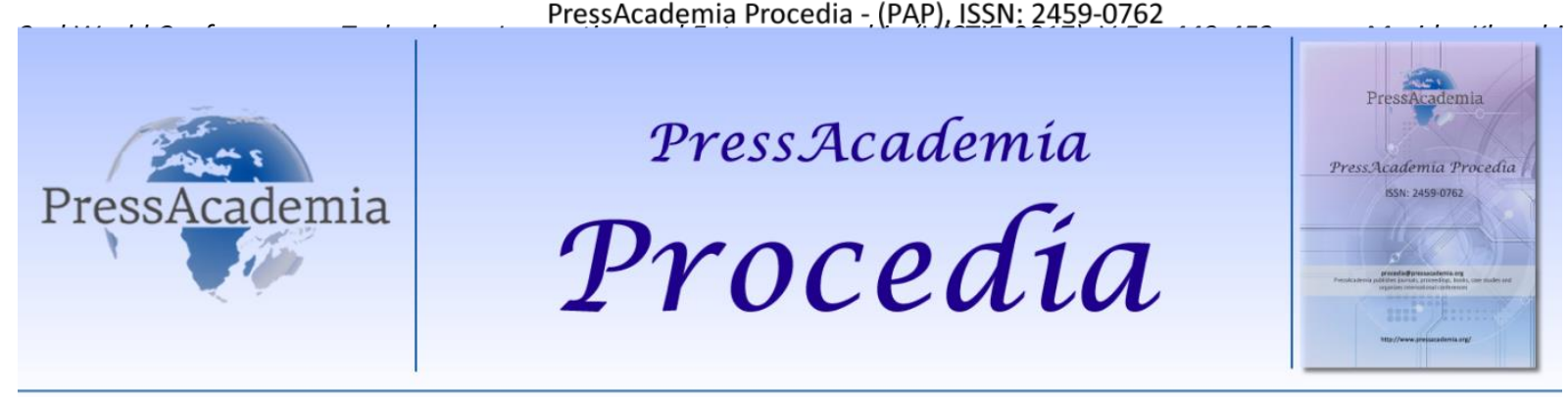

2nd World Conference on Technology, Innovation and Entrepreneurship

May 12-14, 2017, Istanbul, Turkey. Edited by Sefer Şener

\title{
EFFECT OF NATURAL POZZOLAN ON CONCRETE DURABILITY
}

\section{DOI: 10.17261/Pressacademia.2017.623 \\ PAP-WCTIE-V.4-2017(61)-p.449-452}

Ahcene. Merida ${ }^{1}$, Fattoum. Kharchi ${ }^{2}$

${ }^{1}$ University of Bab Ezzouar (USTHB), BP 32 Bab Ezzouar, EL Allia, Algiers, Algeria.merida.hacene@yahoo.fr

${ }^{2}$ University of Bab Ezzouar (USTHB), BP 32 Bab Ezzouar, EL Allia, Algiers, kharchifcong@yahoo.fr

\begin{abstract}
Sulfate attack and its effects are important from both scientific and industrial viewpoints. It is perceived that cements containing pozzolan have better performance in sulfate solutions, since the pozzolanic reactions reduce the quantity of calcium hydroxide and increase calcium silicate hydrate. This paper investigates the physical and mechanical properties of concretes made by blended cement containing Algerian natural pozzolan of volcanic origin, and Portland cement. In order to better determine the pozzolanic effect of the pozzolan addition in the concrete, the analysis of the experimental results of the effect of the partial replacement of the cement by the natural pozzolan showed that it contributes positively to the improvement of its mechanical characteristics, its durability with respect to the permeability to the chlorine ions, the ultrasonic pulse velocity, the compressive strength as well as the sulphate resistance. The present study confirms the pozzolanic reactivity of the natural pozzolan used
\end{abstract}

Keywords: Natural pozzolan, durability, pozzolanic reactivity, sulphate.

\section{INTRODUCTION}

The durability of concrete structures is affected by many environmental factors, the sulphate corrosion being one of the most frequent and detrimental processes.Through the capillary pores of concrete due to the concentration gradient[1,2] and react with unhydrated components of the hardened cement paste. In consequence, these chemical reactions may lead to expansive reaction products such as ettringite $\left(\mathrm{C}_{3} \mathrm{~A} .3 \mathrm{CaSO}_{4} \cdot 32 \mathrm{H}_{2} \mathrm{O}\right)$ [3]. In turn, the ettringite may cause the overall expansion of a structural element and its extensive damage progressing from the outer surface towards the specimen inner core [4].This process may result in a gradual loss of concrete strength [5] accompanied by surface spalling and exfoliation [6].Pozzolanic materials improve the microstructure of concrete due to their particle size, and may alter chemical composition and hydration reactions. Pozzolan as an amorphous or glassy silicate material that reacts with calcium hydroxide formed during the hydration of Portland cement in concrete. The substance that contributes to the strength of the concrete called calcium silicate hydrates(C-S-H) [6]. Calcium hydroxide will reduce the strength of the concrete. Pozzolan contains silica that react with calcium hydroxide in concrete to form extra calcium silicate hydrates compound and diminish calcium hydroxide [7], further strengthening the concrete due to increase of C-S-H compound and making it stronger, denser, and durable during its service life. Many researches on the performance of concretes containing pozzolan in sulfate solutions have been performed [8-10].

The aim of this study is to experimentally investigate the effect of replacing $5 \%$ of cement by natural volcanic pozzolan in the mixture of high performance concrete (HPC) on the compressive strength, permeability to the chlorine ions, sulphate resistance and ultrasonic pulse velocity of specimens exposed to solutions of $5 \%$ sodium sulphate $\left(\mathrm{Na}_{2} \mathrm{SO}_{4}\right)$ in comparison with traditional concrete (CC).

The specimens were stored for one year in drinking water (environment 1) and in aggressive solution containing 5\% sodium sulphate (environment 2). 


\section{EXPERIMENTAL PROGRAM}

\subsection{Materials}

The materials investigated in this paper are: aggregates, cement, natural volcanic pozzolan and superplasticiser.

\subsubsection{Aggregates}

Natural rolled sand obtained from a local river and crushed limestone with a maximum particle size of $16 \mathrm{~mm}$ made fine and coarse aggregates respectively. The size, the finesse modular $\quad(F M=3.2)$, the sand equivalent value $(\mathrm{SEV}=97 \%)$ and resistance to shocks (33\%) confirmed suitability of both aggregates for high performance concrete (HPC).

Sand density $=2,60 \mathrm{~g} / \mathrm{cm}^{3}$

Coarse aggregates Density $=2,50 \mathrm{~g} / \mathrm{cm}^{3}$

\subsubsection{Cement}

Portland cement (CPA-CEM-I / A 42.5) conforming to the Algerian standard NA 443, EN 197-1 and the AFNOR 15-301/94 NFP1 (which is mainly based on the European EN197-1).

Specific gravity $=3100 \mathrm{Kg} / \mathrm{m}^{3}$

Specific surface $=322 \mathrm{~m}^{2} / \mathrm{Kg}$

\subsubsection{Natural Pozzolan}

Natural volcanic pozzolan, extracted from the deposit Beni-saf (Algeria) was used as supplementary cementing material.

Specific gravity $=2660 \mathrm{Kg} / \mathrm{m}^{3}$

Specific surface $=960 \mathrm{~m}^{2} / \mathrm{Kg}$

Pozzolanic activity $=110 \mathrm{mg} \mathrm{CaO} / \mathrm{g}$

The pozzolan content in the mix was fixed at $5 \%$ by weight of cement

\subsubsection{Reducing Superplasticizer}

The study of concrete composition is always to seek simultaneously two essential qualities: strength and workability, but these two qualities are linked to each other but vary in the opposite direction. The idea was to develop a dense concrete from a compact granular skeleton using cement and water and meeting the strength, durability and workability requirements. The optimized superplasticiser content was $2 \%$ at $0.3 \mathrm{~W} / \mathrm{C}$ ratio giving a slump of about $21 \mathrm{~cm}$.

\section{CONCRETES COMPOSITION}

The study of the concrete composition is to define the optimal dosage of aggregates, cement and water to make a concrete with required qualities: strength and durability. This study used "Dreux Gorisse" method of mix proportioning which is based on the size analysis (sand and gravel different fractions) to investigate the use of natural pozzolan on the performance properties of concrete, two different concrete mixes were employed, details of which are given in table 1.The control mix and CC contained only Portland cement, mix of HPC the Portland cement was partially replaced with $5 \%$ natural pozzolan (by weight). All concrete mixtures were prepared according to ASTM C 192 standard. The super plasticizer was added at the time of mixing.

Table 1. Mixture proportions and properties of concrete

\begin{tabular}{|c|c|c|c|c|c|c|c|c|c|}
\hline Concrete & W/ C & Cement, & Pozzolan & Water & Gravel & Gravel & SPa & Sag & Density \\
& & $\mathrm{kg} / \mathrm{m}^{3}$ & $\mathrm{~kg} / \mathrm{m}^{3}$ & $\mathrm{~kg} / \mathrm{m}^{3}$ & $3 / 8$ & $8 / 16$ & $\%$ & $\mathrm{~cm}$ & $\mathrm{~kg} / \mathrm{m}^{3}$ \\
& & & & & $\mathrm{~kg} / \mathrm{m}^{3}$ & $\mathrm{~kg} / \mathrm{m}^{3}$ & & & \\
\hline CC & 0,5 & 425 & 0 & 212,5 & 137 & 837 & 0 & 8 & 2430 \\
\hline HPC & 0.3 & 403.75 & 21.25 & 107.66 & 137 & 837 & 2 & 21 & 2596 \\
\hline
\end{tabular}




\section{TEST METHODS}

Compressive strength: This test was carried out in accordance with ASTM C39.

Chloride permeability: This test was performed using the procedures of ASTM C 1202.

Ultrasonic Pulse Velocity: This test was carried out in accordance with ASTM C597-02.

Sulphate resistance: This test was carried out in accordance with ASTM C1012.

\section{RESULTS}

\section{Fig. 1. Evolution of compressive strengths}

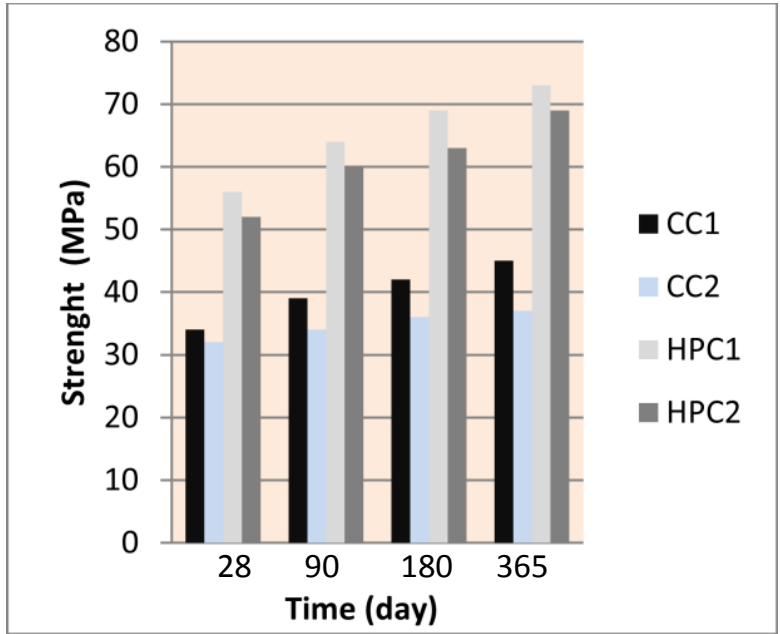

Fig. 3. Variation of velocities

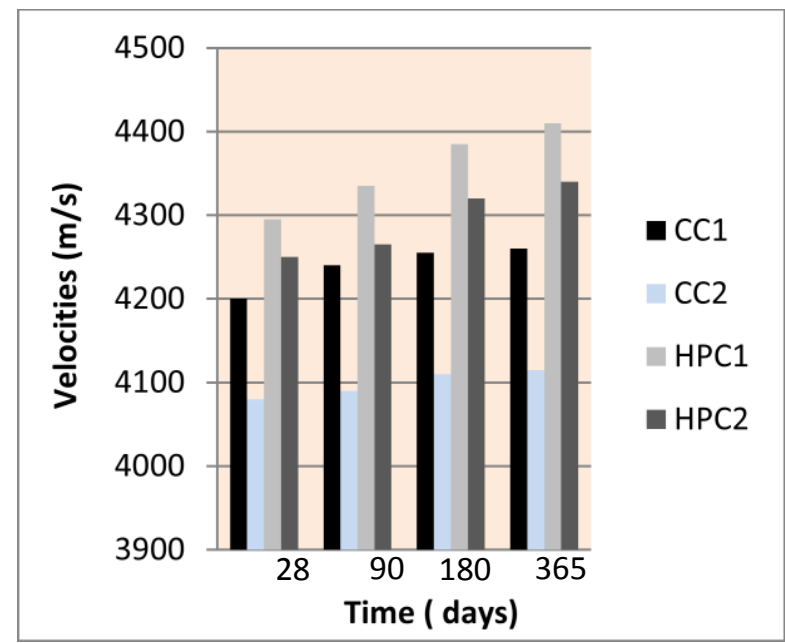

Fig . 4. Results of sulphate resistance
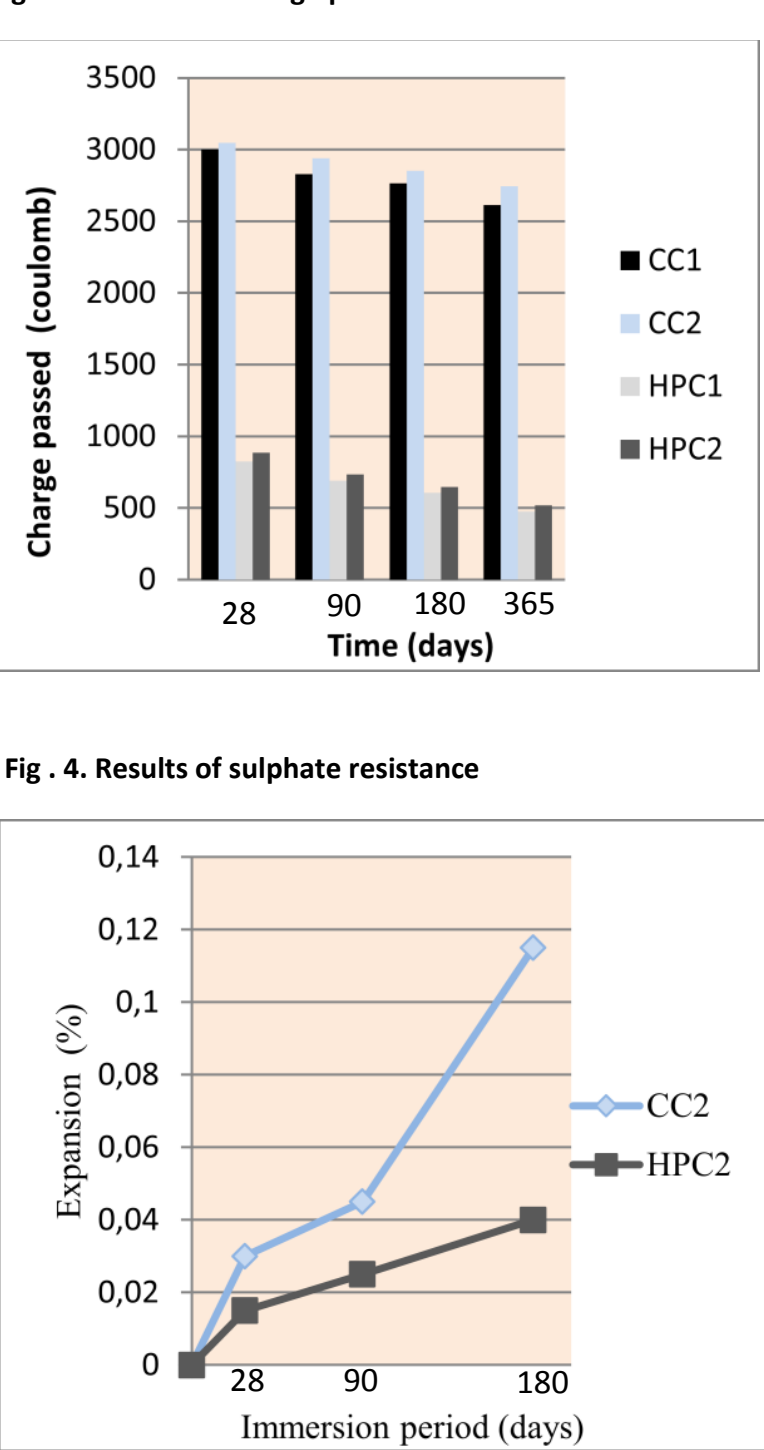

\section{CONCLUSION}

The specimens kept in water, the increase in compressive strength continuous as the duration of immersion increases. The specimen concretes curing in water, the strength of control concrete increase from 34 (MPa) to $45(\mathrm{MPa})$, whereas the high performance concrete it increase from $56(\mathrm{MPa})$ to $73(\mathrm{MPa})$. The results indicates that pozzolan addition helps gain compressive strength.

The specimens kept in aggressive solution; the strength of the control concrete is reduced by $17.77(\%)$ whereas the high performance concrete the reduction was by $(5.48 \%)$ only. 
The specimen concretes curing in water, the charge passed of the control concrete decrease from 3000 (coulomb) to 2614 (coulomb), whereas the high performance concrete it decrease from 825(coulomb) to 476 (coulomb).

The specimens kept in aggressive solution, the charge passed of the control concret is decrease by 4,73 (\%) whereas the high performance concrete the decreasing was by $(8,3 \%)$. The specimen concretes curing in water, the velocities of the control and pozzolan concretes increase from 4200 to $4260(\mathrm{~m} / \mathrm{s})$ and 4295 to $4410(\mathrm{~m} / \mathrm{s})$ respectively in aggressive solution, its decrease by 3, 4 (\%) and 1, $58(\%)$ respectively.

The expansion rates are low at the beginning of the control and high performance concrete, and increases substantially after three months of curing for the first specimen concrete. The expansion of the control concrete and high performance concrete curing in aggressive solution decrease by $65,21(\%)$.

Based on the obtained data in this study, the use of natural volcanic pozzolan replacing (5\%) by weight of cement in the mixture of high performance concrete influences positively the durability specimens concrete cured in sulphate environment. The pozzolan modifies the microstructure of the concrete in terms of its physical and chemical characteristics. It was observed that during the early stages, the filler effect results due to reduction in porosity. With aging, the pozzolanic action further evidence of densification and low porosity of the concrete due to the natural admixture by the formation of $\mathrm{CSH}$ with binding properties similar to those formed in mineral-based cements. I can be concluded that the mineral admixture improved the physical characteristics of concrete relativel to the control concrete sample.

\section{REFERENCES}

[1] Nadler, B. Schuss, Z.Singer, A. Eisenberg, R.S., Ionic Diffusion ThroughProtein Channels: From molecular description to continuum equations, Technical Proceedings of the Nanotechnology Conference and Trade Show, 2003,Vol. 3, pp. 439-442.

[2] Truc, O.,Prediction of Chloride Penetration into Saturated Concrete- Multispecies approach,Chalmers University of Technology, Gutenberg, Sweden, INSA, Toulouse, France2000.

[3] Atkinson, A. Haxby, A. and Hearne, J.A., The Chemistry and Expansion of Limestone-Portland Cement Mortars Exposed to SulphateContaining SolutionsNIREX Report NSS/R127, United Kingdom, 1988.

[4] Skalny,J. Marchand, J. and Odler., I, Sulphate Attack on Concrete, Spon Press, London, United Kingdom, 2002.

[5] Tixier, R.Mobasher, B., Modeling of damage in cement-based materials subjected to external sulfate attack - part 1: formulation. ASCE J Mater Eng,2003, Vol.15, N.4, pp.305-313.

[6] Bentz, DP. Garbicz, EJ.,Simulation studies of the effects of mineral admixtures on the cement paste aggregate interfacial zone. ACl Mater J, 1991,Vol.88, N.5, pp.518-529.

[7] Shamaran, M.Kasap, O.Duru, K. and Yaman, IO., Effect of mix composition and water cement ratio on the sulfate resistance of blended cements, Cement and ConcreteComposites, Vol. 29, $N^{\circ} .3,2007$, pp.159-167.

[8] Saricimen, H.Shameem, M. Barry, MS. Ibrahim, M. and Abbasi, TA.,Durability of proprietary cementitious materials for use in wastewater transport systems, Cement and Concrete Composites, Vol. 25, N²4-5, 2003, pp. 421-427.

[9] Chang, ZT. Song, XJ. Munn, R. and Marosszeky, M.,Using limestone aggregate and different cements for enhancing resistance of concrete to sulfuric acid attack, Cement and Concrete Research, Vol. 35, Nº.8, 2005, pp. 1486-1494.

[10] Sersale, R.Frigione, G. and Bonavita L., Acid depositions and concrete attack: Maininfluences, Cement and Concrete Research, Vol. 28, $\mathrm{N}^{\circ} .1,1998$, pp.19-24 